\title{
Arsenic exposure modifies Fusarium wilt tolerance in grass pea (Lathyrus sativus L.) genotypes through modulation of antioxidant defense response
}

\author{
Dibyendu Talukdar \\ Correspondence: dibyendutalukdar9@gmail.com \\ Plant Cell and Stress Biology Laboratory, Department of Botany, R.P.M. College, University of Calcutta, Uttarpara, Hooghly 712258, \\ West Bengal, India.
}

\begin{abstract}
Background: Arsenic (As) is a toxic metalloid for plant growth while wilt caused by Fusarium is a major yield-limiting factor in grain legumes. Despite immense threat of escalation of major biotic stresses in crops due to contaminated soil, the intrinsic cellular responses to Fusarium wilt under As exposure is not known. Furthermore, the role of primary antioxidant defense other than phenylpropanoid pathway in response to wilt is poorly understood in crop plants.

Methods: Effect of As on wilt tolerance was studied on four genotypes of grass pea (Lathyrus sativus L.) (30 days after commencement of treatment) in a controlled pot experiment with randomized block design in four replicates per four treatment: control (no Fusarium-inoculums, no As in soil), inoculums-treated soil and As + inoculums-treated soil. Data were statistically analyzed at a significant level of $P<0.05$.

Results: In inoculums-treated soil, glutathione (GSH)-deficient gshL-1 mutant wilted but wilting symptom was conspicuously absent in variety BioL-212, ascorbate (AsA)-deficient mutant (asfL-1), and GSH-overproducing mutant. In presence of As, wilting symptoms appeared in BioL-212 and their severity increased in the gshL-1 mutant. Normal activity of phenylalanine ammonia-lyase (PAL) in susceptible gshL-1 mutant and remarkable tolerance of asfL-1 mutant to wilt despite low PAL activity, during As exposure, indicated involvement of antioxidant defense other than PAL in governing wilt sensitivity. Enhanced peroxidase level along with high GSH-redox and low ascorbate peroxidase activity tightly regulated $\mathrm{H}_{2} \mathrm{O}_{2}$ concentration and metabolism in fine tune, effectively preventing oxidative damage of membrane and concomitant escalation of wilting symptom. Low $\mathrm{H}_{2} \mathrm{O}_{2}$ level and deficient peroxidase activity, presumably, weakened $g s h L-1$ defense against fungal invasion. By contrast, under As + inoculums-treated soils, $\mathrm{H}_{2} \mathrm{O}_{2}$ level reached toxic concentration in the mutant and also in variety BioL-212 resulting in onset of oxidative stress and appearance of wilting symptom in the severest form.

Conclusions: As has profound effect on PAL activity and induced/increased wilt symptom through modulation of $\mathrm{H}_{2} \mathrm{O}_{2}$ metabolism within AsA-GSH cycle and outside it. $\mathrm{H}_{2} \mathrm{O}_{2}$ level was found critical in determining tolerance or sensitivity of genotypes to Fusarium wilt, and the GSH-redox state holds the key to manage oxidative damage during pathogenic infection.
\end{abstract}

Keywords: Fusarium wilt, arsenic, phenylalanine ammonia-lyase, AsA-GSH cycle, redox state, peroxidase, $\mathrm{H}_{2} \mathrm{O}_{2}$, Lathyrus sativus L

\section{Introduction}

Phenylalanine ammonia-lyase (PAL) catalyzes the first step in the phenylpropanoid pathway, by deamination of L-phenylalanine to trans-cinnamate and ammonia [1]. In addition to its important roles in plant development, PAL is also a key enzyme in plant stress responses. Its expression and activity is stimulated by diverse types of biotic and abiotic stress factors such as pathogen attack, tissue wounding, extreme temperatures, UV irradiation, nutrient deficiency, plant signaling molecules, including jasmonic acid, salicylic acid and abscisic acid [2,3], salinity [4] and heavy metal toxicity [5]. The production of reactive oxygen species (ROS) is one of the earliest cellular defense responses following successful pathogen recognition $[6,7]$. ROS production is a usual process in an aerobic cell but it may be unbalanced in favor of oxidative state during onset of stress induced by biotic as well as abiotic factors [8]. Ascorbate (AsA)-glutathione (GSH) cycle plays a fundamental role in cellular detoxification of ROS, in which ascorbate peroxidase (APX), dehydroascorbate reductase (DHAR) and glutathione reductase (GR) enzymes scavenge hydrogen peroxide $\left(\mathrm{H}_{2} \mathrm{O}_{2}\right)$, and regenerate $\mathrm{AsA}$ and $\mathrm{GSH}$, respectively [8-10]. Nonspecific peroxidases (POX) also function efficiently in $\mathrm{H}_{2} \mathrm{O}_{2}$ metabolism, utilizing diverse substrates during plant growth [10]. Although ROS production, such as hydrogen peroxide $\left(\mathrm{H}_{2} \mathrm{O}_{2}\right)$ and superoxide radicals, has been considered as a prominent defense against phyto pathogen attack $[6,7]$, it must be maintained in a level compatible with plant growth and development $[6,9,10]$. The redox state of both AsA and GSH is far more influential than their amount during stress response [8].

Arsenic (As) is a ubiquitous toxic metalloid without biological functions in higher plants. Being an analogue of phosphate, arsenate is able to compete and is readily taken up by plants through high-affinity phosphate transporters of root membranes [11]. 
In recent times, the impact of irrigation with high As contaminated ground water on soil and crops has drawn huge attention due to transfer of As to the food chain via the groundwater-soil-plant system [12]. Grass pea (Lathyrus sativus L.) is a cool-season legume crop, cultivated in a very low-input condition for both food and fodder in the Indian sub-continent, sub-Saharan Africa, Mediterranean regions, South America, parts of Europe and Australia [13] and this crop undergoes diverse types of biotic and abiotic stresses [14]. Growing evidences indicate that As can be significantly accumulated in grain and forage legumes $[15,16]$ and it induces oxidative stress [17-19]. Recent reports indicated that As-exposure greatly facilitated invasive potentials of Leucaena sp and increased weed-induced phytotoxicity in grass pea and lentil $[\mathbf{2 0}, \mathbf{2 1}]$. In grass pea, As-exposure significantly reduced seed germination, inhibited photosynthetic activities and plant growth but significantly enhanced the level of seed neurotoxin, $\beta$-ODAP ( $\beta$-N-Oxalyl-L $\alpha, \beta$-diamino propionic acid) $[22,23]$. In recent years, promising mutant lines and genotypes exhibiting novel cytogenetic features, desirable agronomic traits and particular mechanism of antioxidant defense have been isolated and characterized in grass pea [24-32]. Mutational strategy provides a powerful tool to analyze the responses of various Arabidopsis mutants like cad2, rax1-1 and pad 2 and their double and triple mutants to various bacterial, fungal and oomycete pathogens as well as to insects [33-35]. Roles of antioxidant defense components like flavonoids, ascorbateglutathione cycle enzymes, and catalase have been elucidated in legume mutants $[36,37]$, and have been mapped along with morphological and isozyme markers [38,39].

Wilt caused by Fusarium spp is a major biotic stress factor for low crop productivity and yield instability in various food legumes including grass pea [40]. F. oxysporum is a soil borne, root pathogen colonizing the vessels and blocking them completely to effect wilting [40]. It affects the susceptible cultivars within 20 days after sowing and infected seedlings exhibit drooping of leaves, xylem and stem discoloration and root rotting followed by complete collapse. Major grass pea growing areas in several countries including Indian subcontinent are now As-contaminated where yield losses by Fusarium wilt are also prevalent [41]. However, it is unclear whether As-exposure can induce/escalate Fusarium wilt in grass pea cultivated in contaminated soil, and if so, whether PAL activity is exclusively involved in intrinsic modulation of plant response to wilting. Mutation analysis revealed major insight during antioxidant defense responses to pathogenecity in Arabidopsis [8]. Evidence that glutathione is involved in defense against biotic stress came from the studies of Arabidopsis mutants altered in GSH synthesis or metabolism [8]. Despite immense possibility of induction/escalation of biotic stress conditions under As-exposure, no similar information is available regarding agronomically important plant species. Furthermore, virtually nothing is known about involvement of primary antioxidant defense other than PAL during plant- pathogen interaction in contaminated soil. The present study was therefore undertaken to ascertain the effect of As on wilting phenomenon of grass pea genotypes and to explore the roles of PAL and AsA-GSH-cycle enzymes as well as AsA and GSH-redox in modulation of plant response to wilting under As-exposure. The present investigation should provide the first evidence that PAL activity is not exclusively involved in modulation of plant response to Fusarium wilt in legume crop rather PAL activity was modulated through a well integrated response of AsA-GSH cycle enzymes and peroxidase in $\mathrm{H}_{2} \mathrm{O}_{2}$ metabolism as evidenced by the response of four genotypes to Fusarium wilt.

\section{Materials and methods}

\section{Collection and inoculums preparation}

Culture of Fusarium oxysporum f. sp. lentis causing wilt disease in grass pea and lentil was obtained from a local agricultural experimental station, Kalyani, India. The pathogen inoculum was prepared by culturing the fungus on potato dextrose agar medium for 7 days in Petri dishes at $25 \pm 1^{\circ} \mathrm{C}$. The micro conidial suspension was prepared by pouring $20 \mathrm{ml}$ of sterile distilled water in each Petri dishes. The concentration of micro-conidia was adjusted to 1000 conidia $\mathrm{ml}^{-1}$.

\section{Plant materials and growth conditions}

Dry and healthy seeds of four grass pea (Lathyrus sativus L.) genotypes were used and namely one ascorbate (AsA)deficient semi-dwarf mutant (asfL-1) containing only $42 \%$ of leaf and $20 \%$ of root AsA content of variety BioR-231 [42], one glutathione (GSH)-deficient mutant ( $g s h L-1$ ) with $15 \%$ of total glutathione in leaves and $20 \%$ of that in roots of variety BioL212 [43] and one GSH-overproducing mutant exhibiting >2.5fold increase in foliar GSH-content and enhanced antioxidant capabilities compared to its mother variety BioR-231 [44]. Seeds were surface-sterilized with $0.01 \%$ aqueous $\mathrm{HgCl}_{2}$ for 1-2 min, thoroughly washed with double distilled water and then are put to germinate. The grass pea variety BioL-212 has been used as mother variety in the present experiment. Five germinated seeds per genotypes were sown in $30 \mathrm{~cm}$ pots, filled with air dried soil $(5.5 \mathrm{~kg}$, top soil of $0-20 \mathrm{~cm}$ of Alfisols sampled from Gangetic West Bengal, India, $15 \mathrm{~m}$ above sea level, $88.35^{\circ} \mathrm{E} / 22.67^{\circ} \mathrm{N}$, clay_alluvial brown soil, $\mathrm{pH} 6.3$, soil : water ratio of $1: 2.5$, organic matter $5.17 \mathrm{~g} / \mathrm{kg}$ soil, Kjeldahl N $750 \mathrm{mg} / \mathrm{kg}$ soil, $P_{\text {Olsen }} 14.18 \mathrm{mg} / \mathrm{kg}$ soil, available $\mathrm{K} 77.67 \mathrm{mg} / \mathrm{kg}$, available $S 13.80 \mathrm{mg} / \mathrm{kg}$ ) [18], and after 10 days of growth they were finally thinned to two seedlings per pot. The plants ( 10 d-old) were, then, subjected to the following four treatments: (a) control (all four genotypes in non-infested soil and no arsenate), (b) inoculums-treated (pot filled with sterilized $F$. oxysporum infested soil at the rate of $100 \mathrm{ml}$ homogenized culture per pot, 5 day before planting), (c) $50 \mu \mathrm{M}$ sodium arsenate (As, MW $312.01 \mathrm{~g} / \mathrm{mol}$; technical grade, purity $98.5 \%$, Sigma-Aldrich, Bangalore, India) added in already infested soil, and (d) As + plant. Pilot experiment was carried out to 
differentiate sensitive genotypes from tolerant ones under combined exposure of As and inoculum, and $50 \mu \mathrm{M}$ of As was found most effective to generate response which can be used as determining criteria between sensitive and tolerant genotypes, and thus was selected for the present study. The pots were arranged in randomized block design in controlled growth chamber under a $14-\mathrm{h}$ photoperiod, $28 / 18\left( \pm 2^{\circ} \mathrm{C}\right)$, relative humidity of $70 \pm 2 \%$ and a photon flux density of 150 $\mu \mathrm{mol} \mathrm{m} \mathrm{m}^{-2} \mathrm{~s}^{-1}$ in four replicates per treatment. Control and treated plants were allowed to grow for another $30 \mathrm{~d}$ and data were recorded as days after commencement of treatment (DAC). Pots were refreshed every two days to prevent depletion of biotic (inoculums) and abiotic (As) inducers in the course of the plant's exposure to them. Normal agricultural practices were performed. Plants were harvested and shoot tissues were used for further assays.

\section{Enzyme extraction and activity assay}

Fresh shoot tissue $(250 \mathrm{mg}$ ) was homogenized in $1 \mathrm{ml}$ of 50 $\mathrm{mM}$ potassium phosphate buffer $(\mathrm{pH}$ 7.8) containing $1 \mathrm{mM}$ EDTA, $1 \mathrm{mM}$ dithiotreitol, and $2 \%(\mathrm{w} / \mathrm{v}$ ) polyvinyl pyrrolidone (PVP) using chilled mortar and pestle kept in ice bath. The homogenate was centrifuged at $15,000 \mathrm{~g}$ at $4^{\circ} \mathrm{C}$ for $30 \mathrm{~min}$. Clear supernatant was used for enzyme assays. For measuring APX (ascorbate peroxidase) activity, the tissue was separately ground in homogenizing medium containing $2.0 \mathrm{mM}$ ascorbate in addition to the other ingredients. All assays were performed at $0-4^{\circ} \mathrm{C}$. Soluble protein content was determined according to Bradford [45] using Bovine Serum Albumin as a standard.

APX (EC: 1.11.1.11) activity was assayed following Nakano and Asada method [46]. Three milliliters of the reaction mixture contained $50 \mathrm{mM}$ potassium phosphate buffer $(\mathrm{pH} 7.0), 0.1$ mM EDTA, $0.5 \mathrm{mM}$ AsA, $0.1 \mathrm{mM} \mathrm{H}_{2} \mathrm{O}_{2}$ and $0.1 \mathrm{ml}$ of enzyme extract. The hydrogen peroxide-dependent oxidation of AsA was followed by a decrease in the absorbance at $290 \mathrm{~nm}$ $\left(\varepsilon=2.8 \mathrm{mM}^{-1} \mathrm{~cm}^{-1}\right)$. APX activity was expressed as $\mu \mathrm{mol}$ AsA oxidized $\mathrm{min}^{-1} \mathrm{mg}^{-1}$ protein.

DHAR (EC 1.8.5.1) activity was measured following the protocol of Nakano and Asada [46]. The complete reaction mixture contained $50 \mathrm{mM}$ potassium phosphate buffer ( $\mathrm{pH} 7.0)$, $2.5 \mathrm{mM} \mathrm{GSH}, 0.2 \mathrm{mM}$ DHA and $0.1 \mathrm{mM}$ EDTA in a final volume of $1 \mathrm{ml}$. Reaction was started by adding suitable aliquots of enzyme extract and the increase in absorbance was recorded at $30 \mathrm{~s}$ intervals for $3 \mathrm{~min}$ at $265 \mathrm{~nm}$. Enzyme activity was expressed as $\mu \mathrm{mol}$ AsA formed $\mathrm{min}^{-1} \mathrm{mg}^{-1}$ protein.

Glutathione reductase (GR, EC: 1.6.4.2) activity was determined by monitoring the glutathione dependant oxidation of NADPH, as described by Carlberg and Mannervik [47]. In a cuvette, $0.75 \mathrm{ml} 0.2 \mathrm{M}$ potassium phosphate buffer $(\mathrm{pH} 7.0)$ containing $2 \mathrm{mM}$ EDTA, $75 \mu \mathrm{IADPH}(2 \mathrm{mM})$, and $75 \mu$ loxidized glutathione $(20 \mathrm{mM})$ were mixed. Reaction was started by adding $0.1 \mathrm{ml}$ enzyme extract and the decrease in absorbance at $340 \mathrm{~nm}$ was monitored for $2 \mathrm{~min}$. GR specific activity was calculated as nmol NADPH oxidized $\mathrm{min}^{-1} \mathrm{mg}^{-1}$ protein using an extinction coefficient of $6.2 \mathrm{mM}^{-1} \mathrm{~cm}^{-1}$.

POX (EC 1.11.1.7) was measured by monitoring oxidation of $4 \mathrm{mM}$ guaiacol at $470 \mathrm{~nm}\left(\varepsilon=22.6 \mathrm{mM}^{-1} \mathrm{~cm}^{-1}\right)$ in $50 \mathrm{mM}$ potassium-phosphate buffer ( $\mathrm{pH}$ 6.5), after addition of 1 $\mathrm{mM} \mathrm{H}_{2} \mathrm{O}_{2}$ [42]. Enzyme activity was expressed as $\mu \mathrm{mol} \mathrm{mg}$ 1 (protein) min $^{-1}$.

Phenylalanine ammonia-lyase (PAL, EC: 4.3.1.5) activity was determined following the direct spectrophotometric method adopted by Cavalcanti et al., [48]. Two hundred microlitres of the crude enzyme extract previously dialyzed overnight with 100 $\mathrm{mM}$ Tris- $\mathrm{HCl}$ buffer, $\mathrm{pH} 8.8$, were mixed to a solution containing $200 \mu \mathrm{l} 40 \mathrm{mM}$ phenylalanine, $20 \mu \mathrm{l} 50 \mathrm{mM} \beta$-mercaptoethanol and $480 \mu \mathrm{l} 100 \mathrm{mM}$ Tris-HCl buffer, $\mathrm{pH}$ 8.8. After incubation at $30^{\circ} \mathrm{C}$ for $1 \mathrm{~h}$, the reaction stopped by adding $100 \mu \mathrm{l} 6 \mathrm{~N}$ $\mathrm{HCl}$. Absorbance at $290 \mathrm{~nm}$ was measured and the amount of trans-cinnamic acid formed was evaluated by comparison with a standard curve (0.1-2 mg trans-cinnamic acid/ml) and expressed as $\mu \mathrm{g}$ of trans-cinnamic acid $\mathrm{h}^{-1} \mathrm{mg}^{-1}$ protein.

\section{Determination of AsA and GSH content and their redox states}

Reduced and oxidized form of ascorbate and glutathione were measured according to methods of Law et al., [49] and Griffith [50], respectively, and their redox state was calculated as AsA/ (AsA+DHA) and GSH/(GSH+GSSG), respectively.

\section{Determination of $\mathrm{H}_{2} \mathrm{O}_{2}$ content and lipid peroxidation level}

$\mathrm{H}_{2} \mathrm{O}_{2}$ was estimated following the method of Wang et al., [51]. Fresh tissue $(0.1 \mathrm{~g})$ was powdered and blended with 3 $\mathrm{ml}$ acetone for $30 \mathrm{~min}$ at $4^{\circ} \mathrm{C}$ and was filtered through eight layers of gauze cloth. After addition of $0.15 \mathrm{~g}$ active carbon, the sample was centrifuged twice at $3,000 \mathrm{~g}$ for $20 \mathrm{~min}$ at $4^{\circ} \mathrm{C}$, then $0.2 \mathrm{ml}_{20} \% \mathrm{TiCl}_{4}$ in $\mathrm{HCl}$ and $0.2 \mathrm{ml}$ ammonia was added to $1 \mathrm{ml}$ of the supernatant. After incubation for 10 $\mathrm{min}$, the compound was centrifuged at 3,000 $\mathrm{g}$ for $10 \mathrm{~min}$, the supernatant was discarded and the pellet was dissolved in $3 \mathrm{ml}$ of $1 \mathrm{M} \mathrm{H}_{2} \mathrm{SO}_{4}$ and absorbance was measured by UV/Vis spectrophotometer (PerkinElmer Lambda 25, Mumbai, India) at $410 \mathrm{~nm} . \mathrm{H}_{2} \mathrm{O}_{2}$ content was measured from the absorbance at $410 \mathrm{~nm}$ using a standard curve. Lipid peroxidation rates were determined by measuring the malondialdehyde (MDA) equivalents according to method of Hodges et al., [52]. About $0.5 \mathrm{~g}$ of fresh tissue was homogenized in a mortar with $80 \%$ ethanol. The homogenate was centrifuged at $3,000 \mathrm{~g}$ for 12 min at $4^{\circ} \mathrm{C}$ to pellet debris. The pellet was extracted twice with the same solvent. The supernatants were pooled and $1 \mathrm{ml}$ of this sample was mixed either with $20 \%$ trichloroacetic acid (TCA) or with a mixture of $20 \%$ TCA, $0.65 \%$ thiobarbituric acid and $0.01 \%$ butylated hydroxy toluene (BHT). Both mixtures were allowed to react in a water bath at $95^{\circ} \mathrm{C}$ for $25 \mathrm{~min}$, cooled to room temperature and centrifuged. Absorbance was measured at 450, 532 and $600 \mathrm{~nm}$ against a blank. Level of lipid peroxides was calculated following Hodges et al., [52] 

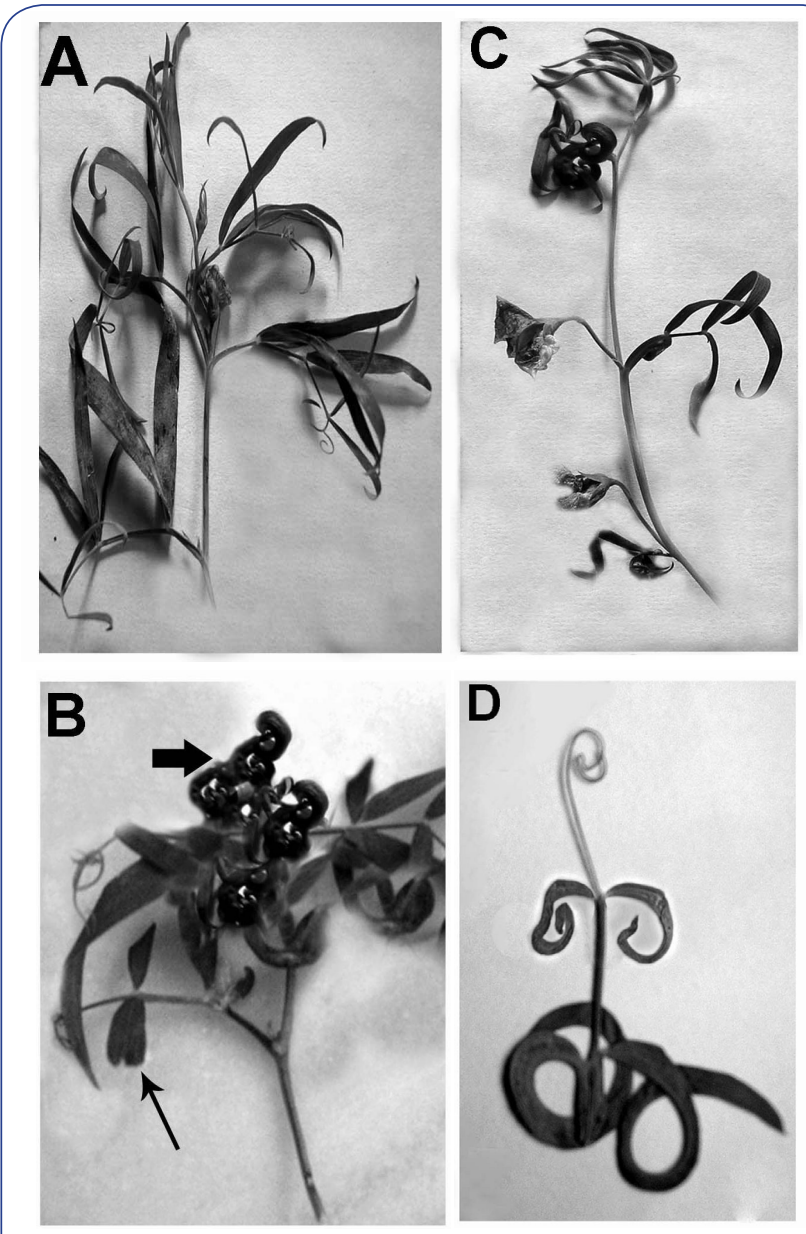

Figure 1. Healthy flowering twig of un-treated grass pea $g s h L-1$ mutant (A) and appearance of severe wilting symptoms exhibiting tuft of rolled crinkled terminal leaflets (bold arrow) and rudimentary leaflets (thin arrow) in the mutant grown in inoculums-treated pot soil (B), and appearance of wilting phenotype in grass pea variety BioL212 (C) and characteristic rolling of all leaflets in $g s h L-1$ mutant (D) under As (sodium arsenate) + inoculumstreated pot soil.

and expressed as nmol MDA g ${ }^{-1}$ fresh weight.

\section{Statistical analysis}

The results presented are the mean values \pm standard errors of at least four replicates. Multiple comparisons of means were performed by ANOVA (SPSS Inc. v. 10), and the means were separated by Duncan's multiple range test considering significant differences at $P<0.05$.

\section{Results}

Effect of Fusarium inoculums and inoculums + As treatment on plant morphology

All the four genotypes of grass pea were quite normal under untreated condition. In inoculums- treated set, wilting symptom was not observed in mother variety BioL-212 and in asfL1 and GSH-overproducing mutants. However, symptoms of Fusarium wilt such as dropping of leaflets, small rudimentary leaflets, extremely wrinkled tuft of terminal leaflets with dense green color and stunted internodes were evident on shoots of 30-d-old GSH-deficient gshL-1 mutant exposed to inoculums (Figure 1A,B).

In As + inoculums-treated soil, mother variety developed severe wilting which was initially manifested as dropping of leaflets on 20 DAC and consequently, as collapse of upper shoot portions with wrinkled leaflets on 30 DAC (Figure 1C). In gshL-1 mutant, the appearance of symptoms were anticipated by 10 days and exhibited as characteristic leaf rolling (Figure 1D), wilting of shoot, withering of leaflets and stipules, and bud drop out on 20 DAC. Wilting symptom was totally absent in asfL-1 mutant and GSH-overproducing mutant. No wilting symptom was observed in any of the four genotypes subjected to As + plant treatment, and thus, the effects of rest three treatment protocols on wilting will be discussed here.

\section{Effect of Fusarium inoculums and inoculums + As treatment on PAL activity}

In inoculums-infested soil without any As, PAL activity was increased in comparison with respective control about 2 -fold in BioL-212, nearly 2.5-fold in asfL-1 and about 3-fold in shoots of GSH-overproducing lines at harvest (Figure 2A). Enzyme activity in all genotypes started to rise at 10DAC, reached its peak at $20 \mathrm{DAC}$, and then became stationary (data not shown). Compared to control, marginal increase in PAL activity was observed in inoculums-treated gshL-1 shoots (Figure 2A). Under exposure to As + inoculums-treated soil, PAL activity was decreased significantly in BioL-212, asfL-1 mutant and gshL-1 shoots in comparison with respective control, while its level was maintained high in GSH-overproducing mutant (Figure 2A).

AsA-GSH cycle enzyme and POX activity in inoculumstreated and As + inoculums-treated materials

Excluding gshL-1 mutant, a substantial decrease of APX activity was observed in BioL-212 and GSH-overproducing mutant exposed to inoculums. Compared to control, APX activity was increased by about 5 -fold in gshL-1 mutant (Figure 2B). The treatment with As + inoculums increased APX activity over control by about 2-fold in BioL-212 but a decrease of 4-4.3fold in gshL-1 and GSH-over producing mutant was detected (Figure 2B). Compared to control, APX activity was nonsignificantly $(P>0.05)$ changed in asfL-1 shoot in both treatments.

Exposure to inoculums led to significant increase in GR activity in BioL-212 and asfL-1, while it was similar to control in GSH-overproducing mutant and decreased by 2.7-fold in gshL-1 mutant (Figure 2C). The treatment with As + inoculums resulted in considerable increase in GR activity in asfL-1 and GSHoverproducing mutant (> 3.0-fold) but the activity decreased by 3.5-fold in BioL-212 and nearly 3-fold in gshL-1 mutant 

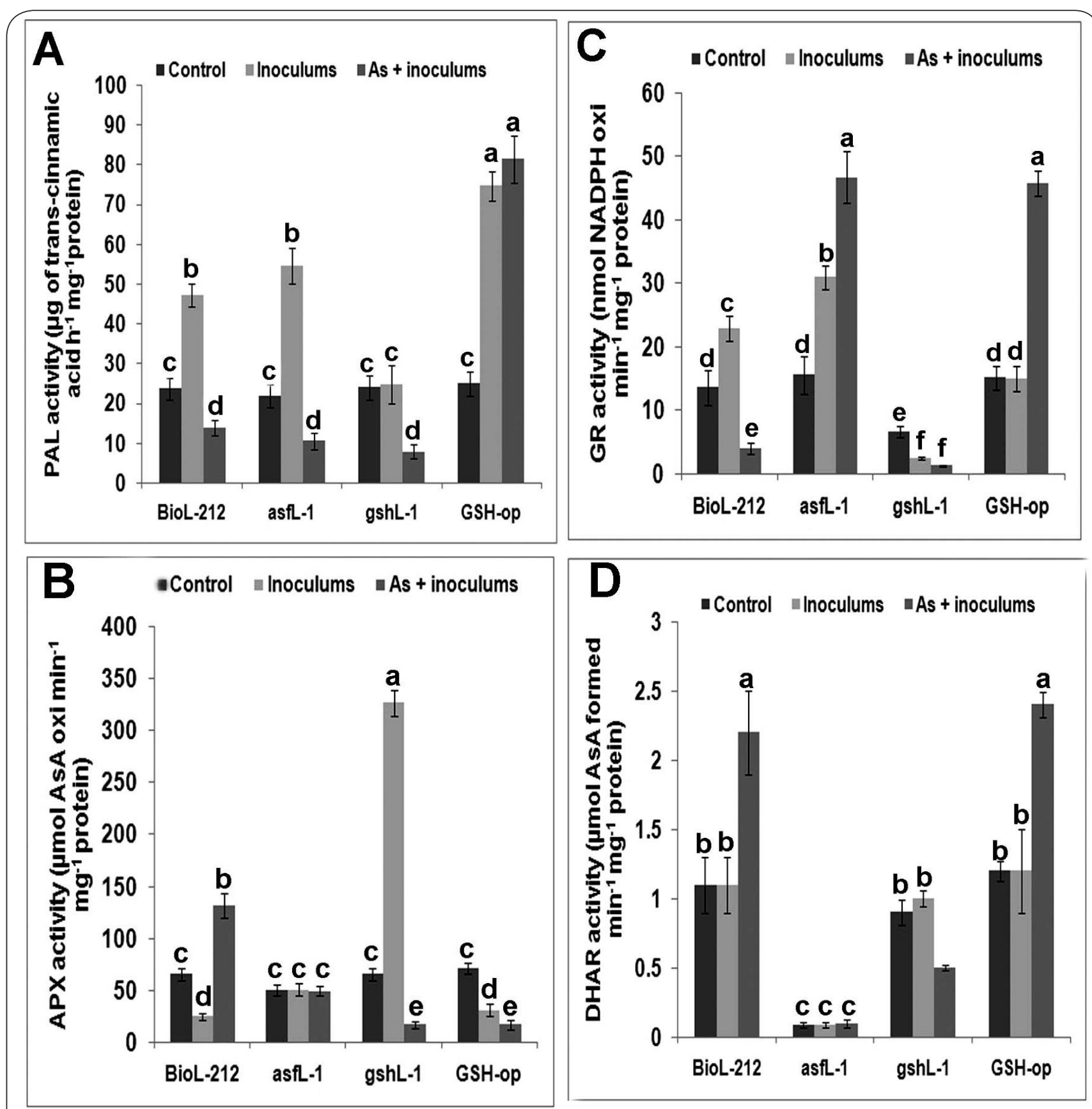

Figure 2. Activities of phenylalanine ammonia-lyase (PAL) (A), ascorbate peroxidase (APX) (B), glutathione reductase (GR) (C), and dehydroascorbate reductase (DHAR) (D) in grass pea variety BioL-212, and three mutant lines, asfL-1, gshL-1 and GSH-op (GSH-overproducing) grown in un-treated control, inoculums-treated and As (sodium arsenate) + inoculums-treated pot soil. Vertical bar represents means $(n=4) \pm$ SE. Means followed by the same letter were not significantly different at $\mathrm{P}<0.05$ by ANOVA followed by Duncan's Multiple Range Test.

(Figure 2C). DHAR activity was constitutively low in asfL1 mutant under un-treated and treated conditions. It was comparable among other genotypes under inoculums-treated condition. The treatment with As + inoculums enhanced DHAR activity over the control nearly 2-fold in both BioL-212 and GSH-overproducing mutant but decreased the activity by 1.8-fold in gshL-1 mutant (Figure 2D).
In comparison to control, activity of guaiacol-peroxidase was 4-fold lower in gshL-1 mutant but it was quite similar in other genotypes exposed to inoculums-treated soil. Treatment with As + inoculums markedly increased (about 3-fold) enzyme activity in asfL-1 shoot. POX activity was unaffected in GSHoverproducing mutant but it was decreased significantly in BioL-212 and gshL-1 mutant (Figure 3A). 

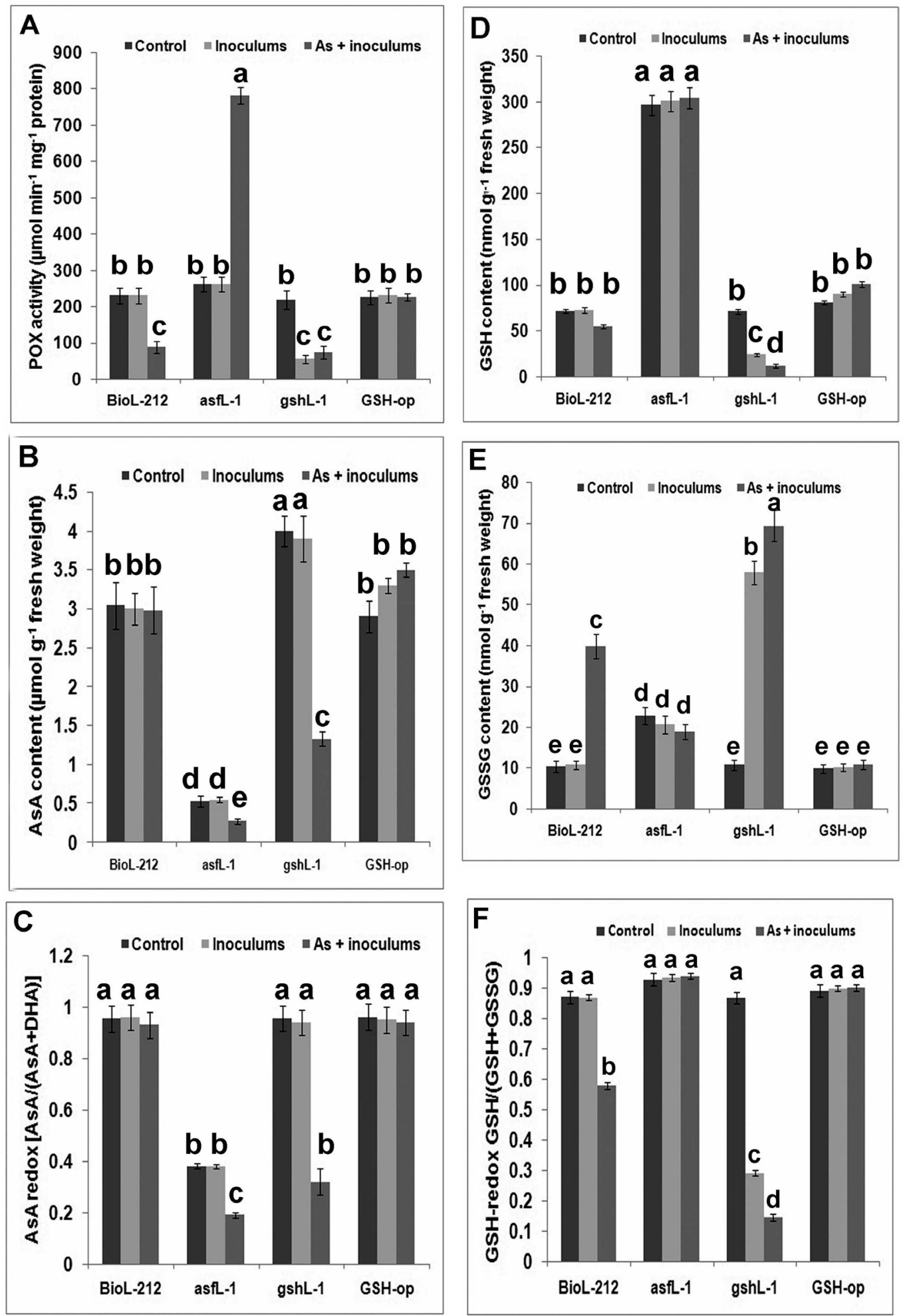

Figure 3. Activities of guaiacol-peroxidase (POX) (A), and reduced ascorbate (AsA) (B), AsA-redox (C), reduced glutathione (GSH) content (D), oxidized glutathione (GSSG) (E) and GSH-redox (F) in seedlings of grass pea variety BioL-212, and three mutant lines, asfL-1, gshL-1 and GSH-op (GSH-overproducing) grown in un-treated control, inoculums-treated and As (sodium arsenate) + inoculums-treated pot soil. Vertical bar represents means $(\mathrm{n}=4) \pm \mathrm{SE}$. Means followed by the same letter were not significantly different at $\mathrm{P}<0.05$ by ANOVA followed by Duncan's Multiple Range Test. 

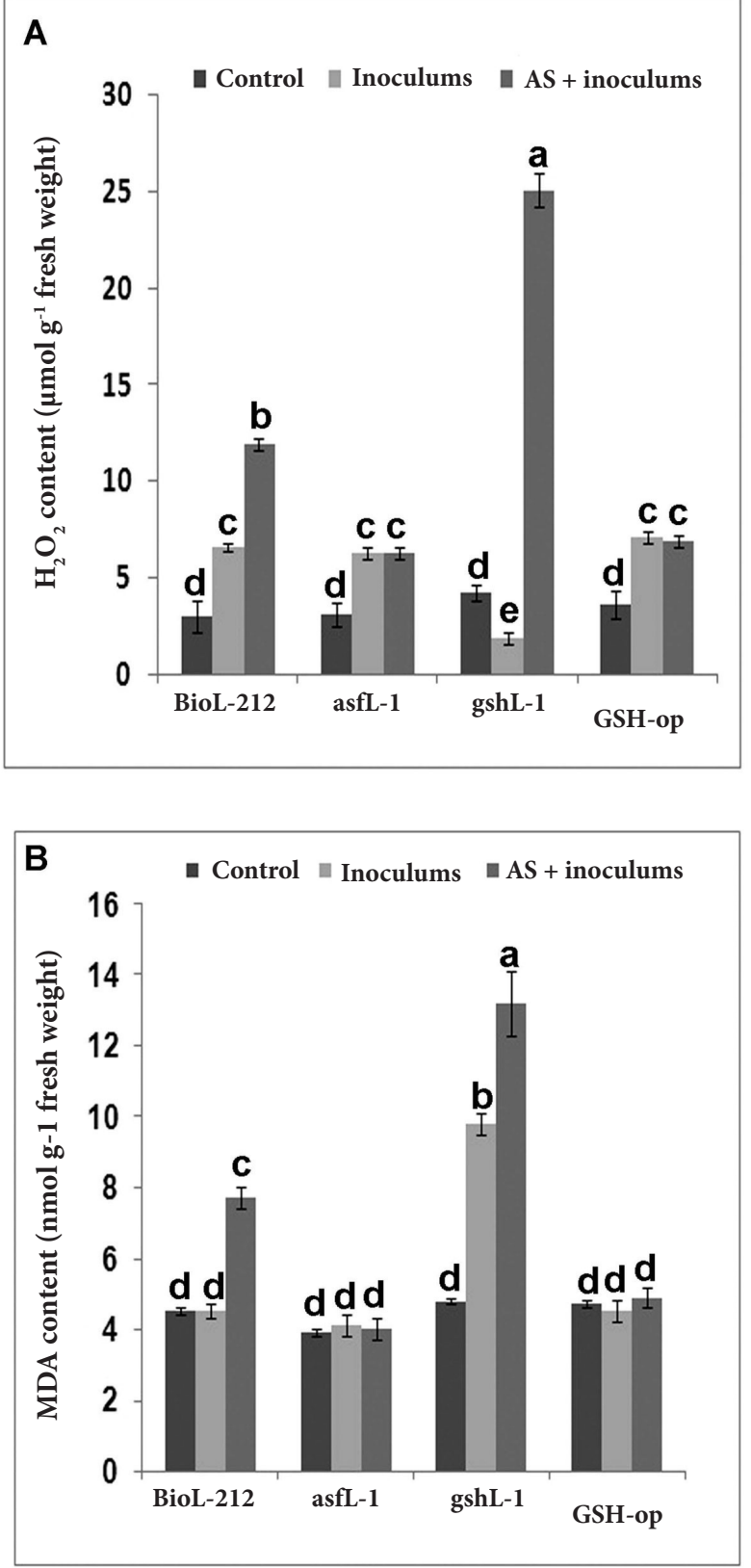

Figure 4. $\mathrm{H}_{2} \mathrm{O}_{2}$ (A) and MDA (B) level in seedlings of grass pea variety BioL-212, and three mutant lines, asfL1, gshL-1 and GSH-op (GSH-overproducing) grown in un-treated control, inoculums-treated and As (sodium arsenate) + inoculums-treated pot soil. Vertical bar represents means $(n=4) \pm$ SE. Means followed by the same letter were not significantly different at $\mathrm{P}<0.05$ by ANOVA followed by Duncan's Multiple Range Test.

Effect of Fusarium inoculums and inoculums + As treatment on AsA and GSH redox

The AsA content and AsA-redox state did not change significantly in all the four genotypes upon exposure to inoculums but they were fallen by about 2 -fold in asfL-1 and about 3-fold in gshL-1 mutants exposed to As + inoculums treatment (Figure 3B,C). The GSH-redox was unchanged in BioL-212 when infected with inoculums alone but it was reduced in As + inoculums treated soil. GSH content was significantly higher in asfL-1 mutant than other three genotypes and it was affected non-significantly in both treatments (Figure 3D). GSH content was reduced significantly in gshL-1 mutant, exposed to inoculums and a further reduction was induced by As + inoculums treatment (Figure 3D). By contrast, GSSG amount was markedly enhanced in inoculums-treated BioL-212 and As + inoculums-treated gshL-1 mutant (Figure 3 E). GSH-redox was quite high in asfL-1 and GSH-overproducing mutant, hovering around 0.9 in both treatment conditions (Figure 3F). Although deficient in total content, GSH-redox was similar to control in gshL-1 mutant in un-treated condition, but it was considerably decreased (3-fold) in seedlings grown in infested soil and even more when As was added in soil (Figure 3 F). The decrease in redox state of both AsA and GSH was mainly carried out by a lowering of their reduced form and/or concomitant increase in their oxidized form (Figure 3F).

\section{Hydrogen peroxide $\left(\mathrm{H}_{2} \mathrm{O}_{2}\right)$ and lipid peroxidation} (malondealdehyde or MDA) contents

Shoot $\mathrm{H}_{2} \mathrm{O}_{2}$ of BioL-212, asfL-1 and GSH-overproducing mutant was increased by about 2.2-fold, 2-fold and 2.5-fold, respectively, in presence of inoculums alone (Figure 4A). Compared to control, shoot $\mathrm{H}_{2} \mathrm{O}_{2}$ content was significantly lower in gshL-1 mutant grown in inoculums-treated pot soil. Upon exposure to $\mathrm{As}+$ inoculums, $\mathrm{H}_{2} \mathrm{O}_{2}$ level was further increased in BioL-212 but was remained unchanged in asfL-1 and GSH-overproducing mutant. By contrast, there was nearly 6-fold rise in tissue $\mathrm{H}_{2} \mathrm{O}_{2}$ level in gshL-1 mutant exposed to As + inoculums-treated soil (Figure 4A).

Measureable MDA content was similar in BioL-212, asfL-1 and GSH-overproducing mutant but it was significantly higher than control in gshL-1 mutant grown in inoculums-treated soil (Figure 4B). However, a significant rise in MDA content was observed in both BioL-212 and gshL-1 mutant with more increase in case of the mutant under As + inoculums-treated soils (Figure 4B). Negligible changes in MDA level were noticed in as $\mathrm{fL} 1$ and GSH-overproducing mutants when compared with control (Figure 4B).

\section{Discussion}

Fusarium wilt is a severe biotic stress factor for yield losses in grain legumes, fruits, vegetables and other economically important crop plants $[\mathbf{5 3}, \mathbf{5 4}]$. In the present study, four grass pea genotypes with contrasting antioxidant defense backgrounds were considered to study the modulation of phenylpropanoid pathway and AsA-GSH cycle, the role of $\mathrm{H}_{2} \mathrm{O}_{2}-$ scavenging enzymes and of two non-enzymatic antioxidants, the AsA and GSH during exposure of Fusarium inoculums and $A s+$ inoculums. In the first pot experiment, in controlled 
and uniform growth condition, results revealed that infested soil triggered major wilting symptoms only in gshL-1 mutant while the other three genotypes did not show significant changes in morphology. Conspicuous absence of wilting in all four genotypes exposed to As alone but the occurrence of wilting in gshL-1 mutant exposed to inoculums only and also increasing its severity under As + inoculums + plant treatment suggested that wilting symptom was not due to the effect of metalloid but its presence in soil increased the severity of wilting caused by Fusarium. This was further substantiated by the fact that BioL-212 showed no wilting in As + plant and inoculums + plant treatments but the plant wilted when As was added along with inoculums in soil. The results suggested apparent tolerance of mother variety BioL-212 and the two mutants, asfL-1 and GSH-overproducing to imposed doses of Fusarium inoculums but indicated a strong susceptibility of gshL-1 mutant to the disease.

In order to ascertain the differential response of four genotypes to Fusarium inoculum, activities of five prominent antioxidant enzymes in plants were tested. Significant increase of PAL activity in BioL-212, asfL-1 and GSH-overproducing mutant strongly suggested pathogen-induced rise of the enzyme activity in conferring protection against wilt. PAL activity was enhanced in wheat plants treated with BTH, a novel systemic acquired resistance inducer in response to powdery mildew infection [55], in ASM-primed resistance in Japanese pear [56] and cucumber [57]. Enhanced PAL activity was also reported in chickpea seedlings treated with Rhizobium Pch43 followed by F. oxysporum f. sp. ciceri race 0 and chemical as well as biological inducers [58], in SA-primed as well as Bacillus-treated tomato plants in response to Fusarium oxysporum [59] and in other crop plants subjected to elicitors and inducers [57-59]. In the present experiment, no external priming or stimuli was used to elicit PAL activity against Fusarium inoculums and no constitutive over-expression of PAL was observed in all considered genotypes under un-treated control. This finding confirmed responsiveness of PAL-mediated primary defense system against Fusarium wilt and also indicated that strain specific to lentil was also able to induce pathogenic response in grass pea.

The susceptibility of gshL-1 mutant to Fusarium wilts despite normal PAL activity was surprising and unique in crop plants, and is not in accordance with the common opinion that in response to invasion of pathogen, PAL activity is enhanced. In order to clarify this apparent conflicting situation and to reveal the involvement of other primary defense mechanism during Fusarium infection, role of defense components of AsA-GSH-cycle and $\mathrm{H}_{2} \mathrm{O}_{2}$-scavenging was investigated in four genotypes of grass pea. These four genotypes, as reported in plant material section, were selected for their distinct differences in antioxidant defense mechanism. In particular mother variety BioL-212 did not show significant differences in redox state of both AsA and GSH and enzyme activities, the asfl-1 mutant was highly deficient in AsA-redox and gshL-1 was deficient in GSH level, while high redox value of GSH was observed in GSH-overproducing mutant in un-stressed condition. More importantly, these three mutant traits are constitutively expressed and inherited as novel stable traits in advanced mutant progenies [42-44]. The primary and significant defense responses of these three mutants are GSH-mediated modulation of $\mathrm{H}_{2} \mathrm{O}_{2}$-metabolism within AsA-GSH cycle and outside it [42-44]. Novelty of different mutants has also been used in model plant Arabidopsis thaliana to dissect antioxidant defense response during plant-pathogen interaction [60]. The results obtained in the present investigation are interesting. In inoculums-treated soil, significant high level of APX and declining activity of POX in gshL-1 mutant suggested a possible involvement of $\mathrm{H}_{2} \mathrm{O}_{2}$ in regulating its disease resistance. Role of $\mathrm{H}_{2} \mathrm{O}_{2}$ as a diffusible ROS in protection against diverse types of pathogen attack and hypersensitive response has been elucidated in different crop plants $[7,61,62]$. Association of $\mathrm{H}_{2} \mathrm{O}_{2}$ with cell wall lignifications, callose synthesis, cell wall cross-linking and in formation of other physical defensive barriers was found during fungal infections [62]. The resistant iso-line Williams-8818-1 of banana exhibited a typical response of first "oxidative burst" during Fusarium infection, in which $\mathrm{H}_{2} \mathrm{O}_{2}$ accumulation was greatly induced [7]. The opposite response of two peroxidases in the gshL-1 mutant considered indicated that $\mathrm{H}_{2} \mathrm{O}_{2}$ is scavenged vigorously by enhanced activity of APX while POX activity was not enough to take part in mechanical strengthening of shoot tissue required to prevent wilt during Fusarium invasion. Role of GR in this process is also worth mentioning. Low GR activity, afecting GSH recycling resulted in abnormal low level of GSH-redox in gshL-1 shoot which inhibited GSH-mediated antioxidant defense. Significant high MDA content suggested onset of oxidative damage of shoot membrane despite normal DHAR activity and AsA-redox in inoculums-treated gshL-1 mutant and strongly indicated that AsA-GSH cycle enzymes and GSH-redox are more involved rather than AsA during pathogen infection. This observation was further confirmed by the facts that in other three genotypes exhibiting tolerance to wilting APX activity was low but POX and GR activities along with GSHredox were normal to high. $\mathrm{H}_{2} \mathrm{O}_{2}$ has the ability to modulate the activity of APX and POX in stressed cell [42], and its dual role as stress-inducer and in ROS-signaling to up-regulate antioxidant defense has been elucidated in different crop plants $[9,10,18,19]$. In tomato, salicylic acid -mediated inactivation of $\mathrm{H}_{2} \mathrm{O}_{2}$ - degrading enzymes invoked hypersensitive cell death. Similar situation was reported in jasmonic acid-treated pepper and tomato plants during Fusarium infection [61]. Presumably, ROS were proposed to act synergistically in a signal amplification loop with external or internal stimuli to drive the hypersensitive reaction and the establishment of systemic defense [62]. In the present investigation $\mathrm{H}_{2} \mathrm{O}_{2}$ level was increased in BioL-212, asfL-1 and GSH -overproducing mutant, but MDA level was quite similar in all three cases. Although a positive correlation between rise of $\mathrm{H}_{2} \mathrm{O}_{2}$ level and 
increase in lipid peroxidation has been reported in many cases $[10,17,21,31,37]$, our results showed an opposite trend. The actual toxicity of ROS in a given plant-pathogen interaction depends on the sensitivity of the pathogen to the concentration of ROS present, but high ROS concentrations are toxic to host plants, too [62]. Obviously, $\mathrm{H}_{2} \mathrm{O}_{2}$ level in the present genotypes showing resistant to wilts was tightly regulated and it represents a critical control point for modulation of antioxidant enzyme activities in favor of mechanical strength as well as prevention of oxidative damage of membrane. This tight regulation of $\mathrm{H}_{2} \mathrm{O}_{2}$ accumulation was not observed in gshL-1 mutant and a declining $\mathrm{H}_{2} \mathrm{O}_{2}$ content was thus unable to trigger antioxidant defense against pathogen attack in inoculums-treated soil. It is noteworthy that enzymatic metabolism in regulation of $\mathrm{H}_{2} \mathrm{O}_{2}$ level in stressed plant also depends on redox status of either AsA or GSH or both [8]. Elevated GR activity in BioL-212 and asfL-1 strongly indicated steady availability of its substrate, the GSSG, produced by DHAR activity when GSH is consumed for detoxification of ROS. GSSG is also generated outside AsA-GSH cycle [42]. Results showed that GSSG level was high in inoculums-treated gshL-1 mutant, indicating significant consumption of GSH during Fusarium infection but the failure of GR activity, due to its constitutively low expression in the mutant led to low GSH-redox which triggered oxidative damage of membrane lipids, as manifested by significantly high MDA content in the treated mutant. By contrast, a normal to high GR activity in three other genotypes showing tolerance to wilting ensured effective regeneration of GSH fundamental in detoxification of lipid peroxides. Present results thus revealed that Fusarium infection alone induced oxidative damage as biotic stress factor and GSH-mediated antioxidant defense in addition to PAL activity played vital roles in conferring resistance to wilting in grass pea genotypes.

The sensitivity of four grass pea genotypes to Fusarium wilts was significantly changed once $50 \mu \mathrm{M}$ As was added in inoculums-treated pot soils. The main objective was to ascertain whether presence of As in soil is able to modify sensitivity and defense mechanism of grass pea genotypes to wilting. Appearance of wilting symptom in BioL-212 and gshL1 mutant indicated their susceptibility to Fusarium infection under As exposure. The effect was more severe in gshL-1 seedlings as symptoms appeared 20 DAC compared to BioL-212 where wilting symptoms developed at 30 DAC. By contrast, a normal growth of asfL-1 and GSH-overproducing mutant in the As + inoculums-treated soil suggested tolerance of two mutants to wilts even in toxic soil. The result was not in accordance with earlier reports regarding induction of resistance against Fusarium wilting by pre-foliar spray with different chemicals and elicitors in tomato [63], in our results As induced wilt susceptibility in BioL-212 and enhanced the symptoms in gshL-1 mutant. The phenomenon of wilting in BioL-212 and gshL-1 mutant and the tolerance in asfL-1 and GSH-overproducing mutant under As exposure were intimately associated with perturbation in intrinsic cellular defense mechanisms. This was expressed by a significant reduction of PAL activity in BioL-212, asfL-1 and gshL-1 mutant and an opposite rise in GSH-overproducing mutant. Despite a low PAL level, in asfL-1 mutant did not develop wilting symptoms under As + inoculums-treated soil. Furthermore, both APX and DHAR activities were also low in the mutant, and AsA-redox was reduced. The remarkable tolerance of this mutant may be related to balanced accumulation of ROS, particularly $\mathrm{H}_{2} \mathrm{O}_{2}$ level along with high level of GR activity and enhanced POX level. Increased GR activity ensured high GSH-redox through efficient recycling of GSH while over-activity of POX might have utilized excess $\mathrm{H}_{2} \mathrm{O}_{2}$ in oxidative cross-linking of cell walls. Overaccumulation of $\mathrm{H}_{2} \mathrm{O}_{2}$ and concomitant increase in membrane damage due to lipid peroxidation are two common symptoms of As-induced oxidative damage and growth inhibition in plants $[31,37] . \mathrm{H}_{2} \mathrm{O}_{2}$ level was significantly increased in asfL-1 mutant but it was comparable to that of inoculums-treated condition and MDA content was unaffected. Presumably, in asfL-1 mutant GSH-redox state rather than PAL activity played key roles in conferring tolerance to As-induced oxidative damage and consequently to fungal infection by maintaining $\mathrm{H}_{2} \mathrm{O}_{2}$ concentration to a level favorable to plant growth. Similar results are also reported in cadmium-treated lentil seedlings, allelopathic interaction and during phytotoxicity $[9,10,17-19,21,64]$. Increasing levels of ROS, built up by either enhanced production and decreased scavenging potential, may contribute to the resistance reaction in tomato against Fusarium wilt [63]. In GSH-overproducing mutant, PAL activity was increased and also POX and GR activities were higher and this may contribute in maintaining normal growth of the mutant through up-regulation of antioxidant defense. On the other hand, increase in severity of wilting symptom in gshL-1 mutant under As + inoculums-treated soil was associated with further decrease in PAL, GR and POX activity. As exposure also decreased APX and DHAR level as well as AsA-redox, indicating total collapse of all antioxidant defense components in the mutant. Consequently, high $\mathrm{H}_{2} \mathrm{O}_{2}$ level and MDA content were detected in gshL-1 shoots determining the highest degree of wilting symptom in comparison with other genotypes tested.

Besides serving as a ROS-regulator, GSH is the exclusive precursor of phytochelatins (PCs), a thiol peptide formed in response to metal stress including As [8], and is used as a reductant by arsenate reductase during conversion of As $V$ to As III in plant tissue [65]. This As III can readily react with thiol-containing enzymes and proteins, and form PC-As III complexes [65]. Although molecular mechanism is still debated, GSH-dependent arsenate reductase activity in the form of glutaredoxin, a ubiquitous oxidoreductase who uses reducing power of GSH to catalyze disulfide reactions in the presence of GR, was manifested in Arabidopsis, Oryza and Pteris vittata exposed to As in different magnitudes [66,67]. Earlier studies revealed that due to low expression of GR activity, GSH as well as PCs level is constitutively low in the present gshL-1 mutant [43]. Preliminary experiments pointed out significant 
lower level of PCs and GSH-S-transferase (GSTs) activity in gshL-1 mutant during As + inoculums treatment compared to control [Talukdar, unpublished]. Metal chelation through $\mathrm{PCs}$ is an important defense strategy in metal homeostasis as PC-deficient Arabidopsis mutants and gshL-1 mutant in grass pea were shown to be hypersensitive to metals like As and cadmium, respectively $[\mathbf{4 3}, \mathbf{6 5}]$. Obviously, low GSH level in gshL-1 mutant during As + inoculums severely affected PCs formation and GSTs activity at substantial magnitude, required for effective conjugation, chelation and subsequent removal of As. On the other hand, accumulation of PCs was much higher and GSTs level was normal in GSH-overproducing mutant under As exposure [Talukdar D, unpublished]. Significant high GSH availability powered by elevated GR activity possibly led to rise in PCs level in GSH-overproducing mutant during As + inoculums which might facilitate better metallaoid-PC complex and subsequent sequestration of $A s$ in the vacuoles. A whole genome transcriptomic analysis in Crambe abyssinica, a member of Brassicaceae, pointed out those PCs, GSTs, DHAR, glutaredoxins and GR are intimately involved in As tolerance [68]. GSTs activity in asfL-1 shoot was constitutively high [42] and PCs level was normal in this mutant during As + inoculums treatment [Talukdar D, unpublished]. Normal PCs level coupled with high GR and GSTs presumably ensured better conjugation and sequestration of As in asfL-1 mutant through better coordination of GSH-mediated antioxidant defense during As + inoculums-treated mutant plants. Present results clearly pointed out that GSH-dependent antioxidant defense is key for differential behavior between gshL-1 and GSH-overproducing as well as asfL-1 mutant during combined exposure to As and fungal inoculums. Presumably, high GSHredox inhibited As-toxicity through up-regulation of antioxidant defense in one hand and efficiently removed As through PCs and/or GSTs in other hand, nullifying fungal infection in tolerant genotypes.

An opposite trend was observed in BioL-212, in which a decrease of PAL activity was associated with an increase in APX and DHAR activities but a concomitant lowering in GR and POX activities. High DHAR activity ensured efficient regeneration of AsA, substrate used by APX as exclusive co-factor during scavenging of $\mathrm{H}_{2} \mathrm{O}_{2}$ within AsA-GSH cycle $[\mathbf{8}, \mathbf{1 8}, \mathbf{2 1}, \mathbf{4 2}, \mathbf{4 6}]$. However, it seems likely that AsA-dependent antioxidant defense (APX, DHAR and AsA-redox) was not able to prevent Fusarium wilting in BioL-212 shoot. This situation got worse when As was added in pot soil. Rise in DHAR activity greatly unbalanced GSH-redox due to continuous consumption of GSH and concomitant generation of GSSG. Moreover, decrease of GR and POX activities severely impeded GSH recycling, resulting in very low $\mathrm{GSH}$-redox and significant rise in $\mathrm{H}_{2} \mathrm{O}_{2}$ level. Depleted GSH level might also be responsible for lower amount of PCs in BioL-212 exposed to As [Talukdar D, unpublished], affecting efficient removal of As and its detoxification. Despite high APX activity, $\mathrm{H}_{2} \mathrm{O}_{2}$ content exceeded the level measured as critical for plant growth in inoculated soil and became toxic to BioL-212, as evidenced by rising MDA content, index of membrane lipid peroxidation in shoots. Excess $\mathrm{H}_{2} \mathrm{O}_{2}$ have been reported to benefit infection by different pathogens, which may even be able to produce ROS themselves or stimulate the host to do so, thereby, facilitating pathogenic invasion through collapse of peroxisomal antioxidant system and destruction of membrane lipids $[6 \mathbf{6 2}, \mathbf{6 9}]$. Present results, thus, clearly indicated that As exposure escalated wilt infection in BioL-212 and gshL-1 shoots by a) negatively interfering with PAL activity, b) reducing capability of GR and POX, c) crippling GSH-mediated antioxidant defense through low GSH-redox and presumably, low PCs, and d) enhancing ROS-induced oxidative damage. However, to what extent excess ROS favored pathogen invasion under metalloid stress, further study is needed to ascertain it.

\section{Conclusions}

For the first time, Fusarium wilt tolerance was tested in grass pea under As exposure. The results clearly indicated that sensitivity to fungal pathogen is not exclusively dependent on phenylpropanoid metabolism; rather it was intimately associated with GSH-mediated antioxidant defense and its redox state. As exposure jeopardized the PAL activity in three out of four genotypes, yet asfL-1 mutant uniquely exhibited remarkable tolerance to wilting and oxidative damage. On the other hand, gshL-1 mutant showed wilting even when PAL activity was normal in inoculums-treated soil. Results revealed that a particular level of $\mathrm{H}_{2} \mathrm{O}_{2}$ is a critical control point for determining tolerance and sensitivity of grass pea genotypes, and GR and POX enzymes played more vital roles compared to PAL. The differential response of antioxidant defense in inoculums-treated soil and As + inoculums-treated condition revealed pronounced effect of toxic metalloid As on plant growth of susceptible genotypes in favoring Fusarium infection through excess generation of ROS. ROS generation was regulated in tolerant genotypes, maintaining an environment favorable to plant growth. The study provided valuable inputs regarding vulnerability of crop plants under combined exposure to both biotic and abiotic stress factors, which can be used in future breeding to design effective ameliorative strategy for multiple stress tolerant crops.

\section{Competing interests}

The author declares no competing interests.

\section{Author's contribution}

Sole author DT designed and executed the experiment, prepared the manuscript, and finally approved the revised manuscript.

\section{Acknowledgement}

Author is grateful to two anonymous reviewers for their valuable suggestions during revision of the manuscript.

\section{Publication history}

Editors: Salah El-Hendawy, Suez Canal University, Egypt. Adele M. Muscolo, Mediterranea University, Italy.

Received: 20-Jun-2013 Revised: 19-Jul-2013

Accepted: 25-Jul-2013 Published: 02-Aug-2013 


\section{References}

1. Dixon RA, Achnine L, Kota P, Liu CJ, Reddy MS and Wang L. The phenylpropanoid pathway and plant defence-a genomics perspective. Mol Plant Pathol. 2002; 3:371-90. | Article | PubMed

2. Chen JY, Wen PF, Kong WF, Pan QH, Zhan JC, Li JM, Wan SB and Huang WD. Effect of salicylic acid on phenylpropanoids and phenylalanine ammonia-lyase in harvested grape berries. Postharvest Biol Technol. 2006; 40:64-72. | Article

3. Huang J, Gu M, Lai Z, Fan B, Shi K, Zhou YH, Yu JQ and Chen Z. Functional analysis of the Arabidopsis PAL gene family in plant growth, development, and response to environmental stress. Plant Physiol. 2010; 153:1526-38. | Article | PubMed Abstract | PubMed Full Text

4. Gao S, Ouyang C, Wang S, Xu Y, Tang L and Chen F. Effects of salt stress on growth, antioxidant enzyme and phenylalanine ammonia-lyase activities in Jatropha curcas L. seedlings. Plant Soil Environ. 2008; 54:374-81. | Website

5. Pawlak-Sprada S, Arasimowicz-Jelonek M, Podgorska M and Deckert J. Activation of phenylpropanoid pathway in legume plants exposed to heavy metals. Part I. Effects of cadmium and lead on phenylalanine ammonia-lyase gene expression, enzyme activity and lignin content. Acta Biochim Pol. 2011; 58:211-6. | Pdf | PubMed

6. De Gara L M, de Pinto and Tommasi F. The antioxidant systems via-a-via reactive oxygen species during plant-pathogen interaction. Plant Physiol Biochem. 2003; 41:863-70. I Article

7. Li W-M, Qian C-M, Mo Y-W, Hu Y-L and Xie J-H. Tolerance of banana for fusarium wilt is associated with early $\mathrm{H}_{2} \mathrm{O}_{2}$ accumulation in the roots. Afr J Biotech. 2011; 10: 11378-87. | Pdf

8. Noctor G, Queval G, Mhamdi A, Chaouch S and Foyer CH. Glutathione. Arabidopsis Book. 2011; 9:e0142. | Article | PubMed Abstract | PubMed Full Text

9. Talukdar D. Exogenous calcium alleviates the impact of cadmiuminduced oxidative stress in Lens culinaris Medic. seedlings through modulation of antioxidant enzyme activities. Journal of Crop Science and Biotechnology. 2012; 15:325-34. | Article

10. Talukdar D. Studies on antioxidant enzymes in Canna indica plant under copper stress. J Environ Biol. 2013; 34:93-8. I Pdf

11. Mehrag NN and Macnair MR. Suppression of the high affinity phosphate uptake system: a mechanism of arsenate tolerance in Holcus lanatus $\mathrm{L}$. J Exp Bot. 1992; 43: 519-24. | Article

12. Azizur Rahman M, Hasegawa H, Mahfuzur Rahman M, Mazid Miah MA and Tasmin A. Arsenic accumulation in rice (Oryza sativa L.): human exposure through food chain. Ecotoxicol Environ Saf. 2008; 69:317-24. | Article I PubMed

13. Kumar S, Bejiga G, Ahmed S, Nakkoul H and Sarker A. Genetic improvement of grass pea for low neurotoxin (beta-ODAP) content. Food Chem Toxicol. 2011; 49:589-600. | Article | PubMed

14. Vaz Patto M C, Skiba B, Pang ECK, Ochatt SJ, Lambein F and Rubiales D. Lathyrus improvement for resistance against biotic and abiotic stresses: From classical breeding to marker assisted selection. Euphytica. 2006; 147:133-47. | Article

15. Gupta DK, Tripathi RD, Mishra S, Srivastava S, Dwivedi S, Rai UN, Yang XE, Huanji $\mathrm{H}$ and Inouhe M. Arsenic accumulation in root and shoot vis-a-vis its effects on growth and level of phytochelatins in seedlings of Cicer arietinum L. J Environ Biol. 2008; 29:281-6. | PubMed

16. Talukdar D. Bioaccumulation and transport of arsenic in different genotypes of lentil (Lens culinaris Medik.). Int J Pharm Bio Sci. 2013; 4:694-701. | Pdf

17. Talukdar D. Arsenic-induced oxidative stress in the common bean legume, Phaseolus vulgaris $\mathrm{L}$. seedlings and its amelioration by exogenous nitric oxide. Physiol Mol Biol Plants. 2013; 19:69-79. | Article

18. Talukdar D. Arsenic-induced changes in growth and antioxidant metabolism of fenugreek. Russ J Plant Physiol. 2013; 60:691-9. | Website

19. Mascher R, Lippmann B, Holzinger S and Bergmann H. Arsenic toxicity: effects on oxidative stress response molecules and enzymes in red clover plants. Plant Sci. 2002; 163:961-9. | Article
20. Talukdar D. Bioaccumulation, growth and antioxidant defense responses of Leucaena species differing in arsenic tolerance. International Journal of Botany and research. 2013; 3:1-18. I Pdf

21. Talukdar D. Selenium priming selectively ameliorates weed-induced phytotoxicity by modulating antioxidant defense components in lentil (Lens culinaris Medik.) and grass pea (Lathyrus sativus L.). Annual Review \& Research in Biology. 2013; 3:195-212. I Website

22. Talukdar D. Effect of arsenic-induced toxicity on morphological traits of Trigonella foenum-graecum L. and Lathyrus sativus L. during germination and early seedling growth. Current Research Journal of Biological Sciences. 2011; 3:116-23. | Pdf

23. Talukdar $D$. Changes in neurotoxin, $\beta$-N-OXALYL- $L \alpha, \beta$-diaminopropionic acid ( $\beta$-ODAP), level in grass pea (Lathyrus sativus $L$.) genotypes under arsenic treatments. J Appl Biosci. 2012; 38:148-53. | Pdf

24. Talukdar D and Biswas AK. Induced seed coat colour mutations and their inheritance in grass pea (Lathyrus sativus L.). Indian J Genet. 2005; 65:135-6. | Website

25. Talukdar D and Biswas AK. Seven different primary trisomics in grass pea (Lathyrus sativus L.). I Cytogenetic characterization. Cytologia. 2007; 72:385-96. | Article

26. Talukdar D. Cytogenetic characterization of seven different primary tetrasomics in grass pea (Lathyrus sativus L.). Caryologia. 2008; 61:40210. | Pdf

27. Talukdar D. Dwarf mutations in grass pea (Lathyrus sativus L.): Origin, morphology, inheritance and linkage studies. J Genet. 2009; 88:165-75. I Article

28. Talukdar D. Recent progress on genetic analysis of novel mutants and aneuploid research in grass pea (Lathyrus sativus L.). Afric J Agric Res. 2009; 4:1549-59. | Pdf

29. Talukdar D. Reciprocal translocations in grass pea (Lathyrus sativus L.). Pattern of transmission, detection of multiple interchanges and their independence. J Hered. 2010; 101:169-76. I Pdf

30. Talukdar D. Cytogenetic analysis of a novel yellow flower mutant carrying a reciprocal translocation in grass pea (Lathyrus sativus L.). Journal of Biological Research-Thessaloniki. 2011; 15:123-34. I Pdf

31. Talukdar D. Isolation and characterization of NaCl-tolerant mutations in two important legumes, Clitoria ternatea $\mathrm{L}$. and Lathyrus sativus L.: Induced mutagenesis and selection by salt stress. Journal of Medicinal Plants Research. 2011; 5:3619-28. | Website

32. Talukdar D. Meiotic consequences of selfing in grass pea (Lathyrus sativus L.) autotetraploids in the advanced generations: Cytogenetics of chromosomal rearrangement and detection of aneuploids. The Nucleus. 2012; 55:73-82. | Article

33. Ferrari S, Plotnikova JM, De Lorenzo G and Ausubel FM. Arabidopsis local resistance to Botrytis cinerea involves salicylic acid and camalexin and requires EDS and PAD2, but not SID2, EDS5 or PAD4. Plant J. 2003; 35:193-205. | Pdf

34. Parisy V, Poinssot B, Owsianowski L, Buchala A, Glazebrook J and Mauch F. Identification of PAD2 as a gamma-glutamylcysteine synthetase highlights the importance of glutathione in disease resistance of Arabidopsis. Plant J. 2007; 49:159-72. | Article | PubMed

35. Schlaeppi K, Bodenhausen N, Buchala A, Mauch F and Reymond P. The glutathione-deficient mutant pad2-1 accumulates lower amounts of glucosinolates and is more susceptible to the insect herbivore Spodoptera littoralis. Plant J. 2008; 55:774-86. | Article | PubMed

36. Talukdar D. The aneuploid switch: Extra-chromosomal effect on antioxidant defense through trisomic shift in Lathyrus sativus L. Indian Journal of Fundamental and Applied Life Sciences. 2011; 1:263-73. | Pdf

37. Talukdar $D$ and Talukdar T. Catalase-deficient mutants in lentil (Lens culinaris Medik.): Perturbations in morpho-physiology, antioxidant redox and cytogenetic parameters. International Journal of Agricultural Science and Research. 2013; 3:197-212. | Pdf

38. Talukdar D. Allozyme variations in leaf esterase and root peroxidase isozymes and linkage with dwarfing genes in induced dwarf mutants of grass pea (Lathyrus sativus L.). Int J Genet Mol Biol. 2010; 2:112-20. I $\underline{\text { Pdf }}$ 
39. Talukdar D. Flavonoid-deficient mutants in grass pea (Lathyrus sativus L.): genetic control, linkage relationships, and mapping with aconitase and S-nitrosoglutathione reductase isozyme loci. ScientificWorldJournal. 2012; 2012:345983. | Article | PubMed Abstract | PubMed Full Text

40. Basandrai AK, Basandrai D, Duraimurugan $P$ and Srinivasan T. Breeding for Biotic Stresses. In Pratap A and Kumar J (Eds.) Biology and Breeding of Food Legumes 2011, 220-40. | Book

41. Campbell C G: Grass pea. Lathyrus sativus L. Promoting the conservation and use of underutilized and neglected crops 1997, 18. Institute of Plant Genetics and Crop Plant Research, Gatersleben/ International Plant Genetic Resources Institute, Rome, Italy. I Book

42. Talukdar D. Ascorbate deficient semi-dwarf asfL1 mutant of Lathyrus sativus exhibits alterations in antioxidant defense. Biol plant. 2012; 56: 675-82. | Article

43. Talukdar D. An induced glutathione-deficient mutant in grass pea (Lathyrus sativus L.): Modifications in plant morphology, alteration in antioxidant activities and increased sensitivity to cadmium. Bioremediation, Biodiversity and Bioavailability. 2012; 6:75-86. | Website

44. Talukdar D. A glutathione-overproducing mutant in grass pea (Lathyrus sativus L.): Alterations in glutathione content, modifications in antioxidant defense response to cadmium stress and genetic analysis using primary trisomics. International Journal of Recent Scientific Research. 2012; 3:234-43. | Article

45. Bradford MM. A rapid and sensitive method for the quantitation of microgram quantities of protein utilizing the principle of protein-dye binding. Anal Biochem. 1976; 72:248-54. | Article | PubMed

46. Nakano $Y$ and Asada K. Hydrogen peroxide is scavenged by ascorbate specific peroxidase in spinach chloroplast. Plant Cell Physiol. 1981; 22:867-80. | Article

47. Carlberg I and Mannervik B. Glutathione reductase. Methods Enzymol. 1985; 113:484-90. I PubMed

48. Cavalcanti FR, Resendea MLV, Carvalhoc CPS, Silveirab JAG and Oliveira JTA. An aqueous suspension of Crinipellis perniciosa mycelium activates tomato defense responses against Xanthomonas vesicatoria. Crop Prot. 2007; 6:729-38. | Article

49. Law MY, Charles SA and Halliwell B. Glutathione and ascorbic acid in spinach (Spinacia oleracea) chloroplasts. The effect of hydrogen peroxide and of Paraquat. Biochem J. 1983; 210:899-903. | Pdf | PubMed Abstract | PubMed Full Text

50. Griffith OW: Glutathione and glutathione disulfide. In Bergmeyer HU (Ed) Methods of Enzymatic Analysis 1985, 521-9. | Book

51. Wang $C Q$, Chen $M$ and Wang BS. Betacyanin accumulation in the leaves of $\mathrm{C}_{3}$ halophyte Suaeda salsa $\mathrm{L}$. is induced by watering roots with $\mathrm{H}_{2} \mathrm{O}_{2}$. Plant Sci. 2007; 172:1-7. | Article

52. Hodges DM, Delong JM, Forney CF and Prange RK. Improving the thiobarbituric acid-reactive substances assay for estimating lipid peroxidation in plant tissues containing anthocyanin and other interfering compounds. Planta. 1999; 207:604-11. | Article

53. Abdel-Monaim MF, Ismail ME and Morsy KM. Induction of systemic resistance of benzothiadiazole and humic Acid in soybean plants against fusarium wilt disease. Mycobiology. 2011; 39:290-8. | Article | PubMed Abstract | PubMed Full Text

54. Abdel-Monaim MF. Improvement of Biocontrol of Damping-off and Root Rot/Wilt of Faba Bean by Salicylic Acid and Hydrogen Peroxide. Mycobiology. 2013; 41:47-55. | Article | PubMed Abstract | PubMed Full Text

55. Stadnik MJ and Buchenauer H. Inhibition of phenylalanine ammonialyase suppresses the resistance induced by benzothiadazole in wheat Blumeria graminis f. sp. tritichi. Physiol Mol Plant Pathol. 2000; 57:2534. | Article

56. Faize $M$, Faize L, Koike N, Ishizaka $M$ and Ishii H. Acibenzolar-smethyl-induced resistance to Japanese pear scab is associated with potentiation of multiple defense responses. Phytopathology. 2004; 94:604-12. | Article | PubMed

57. Cools $\mathrm{HJ}$ and Ishii H. Pre-treatment of cucumber plants with
acibenzolar-S-methyl systemically primes a phenylalanine ammonia lyase gene (PAL 1) for enhanced expression upon attack with a pathogenic fungus. Physiol Mol Plant Pathol. 2002; 61:273-80. | Article

58. Raju S, Jayalakshmi SK, Usharani S and Sreeramulu K. Induction of systemic acquired resistance in susceptible and resistant cultivars of chickpea (Cicer arietinum L) Genotypes: A comparative study in response to salicylic acid and spermine. Physiol Mol Biol Plants. 2007; 13:27-36. | Website

59. Akram W and Anjum T. Quantitative changes in defense system of tomato induced by two strains of Bacillus against Fusarium Wilt. Indian Journal of Fundamental and Applied Life Sciences. 2011; 1:7-13. | Pdf

60. Lorrain S, Vailleau F, Balague $C$ and Roby D. Lesion mimic mutants: keys for deciphering cell death and defense pathways in plants? Trends Plant Sci. 2003; 8:263-71. | Article | PubMed

61. El- Khallal SM. Induction and modulation of resistance in tomato plants against Fusarium wilt disease by bioagent fungi (arbuscular mycorrhiza) and/or hormonal elicitors (Jasmonic acid \& Salicylic acid): 2-Changes in the antioxidant enzymes, phenolic compounds and pathogen relatedproteins. Australian Journal of Basic and Applied Sciences. 2007; 1:71732. | Pdf

62. Shetty NP, Lyngs Jørgensen HJ, Jensen JD, Collinge DB and Shetty HS. Roles of reactive oxygen species in interactions between plants and pathogens. Eur J Plant Pathol. 2008; 121:267-80. | Article

63. Biswas SK, Pandey NK and Rajik M. Inductions of defense response in tomato against Fusarium Wilt through inorganic chemicals as inducers. J Plant Pathol Microb. 2012; 3:128. | Article

64. Talukdar D. Allelopathic effects of Lantana camara L. on Lathyrus sativus L.: Oxidative imbalance and cytogenetic consequences. Allelopathy Journal. 2013; 31:71-90. | Article

65. Norton GJ, Lou-Hing DE, Meharg AA and Price AH. Rice-arsenate interactions in hydroponics: whole genome transcriptional analysis. $J$ Exp Bot. 2008; 59:2267-76. | Article | PubMed Abstract | PubMed Full Text

66. Sundaram S, Rathinasabapathi B, Ma LQ and Rosen BP. An arsenateactivated glutaredoxin from the arsenic hyperaccumulator fern Pteris vittata L. regulates intracellular arsenite. Journal of Biological Chemistry. 2008; 283:6095-101. | Article | PubMed

67. Dhankher OP, Li Y, Rosen BP, Shi J, Salt D, Senecoff JF, Sashti NA and Meagher RB. Engineering tolerance and hyperaccumulation of arsenic in plants by combining arsenate reductase and gammaglutamylcysteine synthetase expression. Nat Biotechnol. 2002; 20:11405. | Article | PubMed

68. Paulose B, Kandasamy S and Dhankher OP. Expression profiling of Crambe abyssinica under arsenate stress identifies genes and gene networks involved in arsenic metabolism and detoxification. BMC Plant Biol. 2010; 10:108. | Article | PubMed Abstract | PubMed Full Text

69. Torres MA, Jones JD and Dangl JL. Reactive oxygen species signaling in response to pathogens. Plant Physiol. 2006; 141:373-8. | Article | PubMed Abstract | PubMed Full Text

Citation:

Talukdar D. Arsenic exposure modifies Fusarium wilt tolerance in grass pea (Lathyrus sativus L.) genotypes through modulation of antioxidant defense response. J Plant Sci Mol Breed. 2013; 2:4.

http://dx.doi.org/10.7243/2050-2389-2-4 